
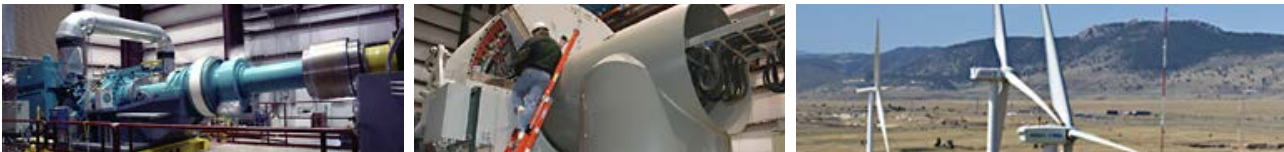

www.nrel.gov/wind

\section{Reducing Bat Fatalities From Interactions with Operating Wind Turbines}

\author{
NREL Studies Differing Hypotheses to Help \\ Solve a Mystery
}

\section{The Puzzle}

One of the biggest advantages of wind energy is that, overall, it has relativity few negative impacts. Nevertheless, most professionals in the wind industry would like to further reduce the impact of energy generation on plants, animals, and their habitats. This is why the industry is highly motivated to find out why migrating bats have unexpectedly high fatality rates near operating wind farms [1], [2].

Given that bats have the remarkable ability to detect and avoid moving objects through echolocation [3], the high fatality rates are somewhat surprising. Regardless, the National Renewable Energy Laboratory (NREL) is working toward a solution. Recent NREL research has shed some new light on what may be causing these bat fatalities, and such information could help solve the mystery and reduce turbine related deaths.

\section{Possible Causes of Turbine-Related Deaths: Collision and Barotrauma}

Trauma from Collision: The most obvious cause of bat deaths around wind turbines is collision with the turbine tower, nacelle, and blades, and indeed many dead bats found around turbines exhibit injuries consistent with impact trauma [4][7]. Some experts have hypothesized that bats have difficulty detecting the fast-moving blades [8], which possibly explains

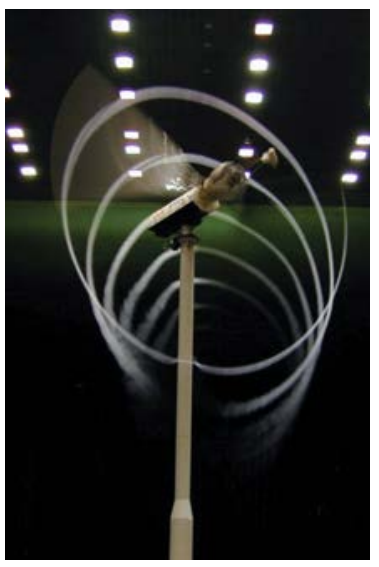
the unexpectedly high fatality rate around operating turbines. A recent study supports this conclusion, by documenting bat collisions with moving turbine blades [9].

Figure 2. The vortex wake of an operating wind turbine shed from the tips of the rotating blades shown using smoke flow visualization. The location of smoke indicates a region of low pressure with respect to atmospheric pressure. Photo by Lee Jay Fingersh, NREL 09996.

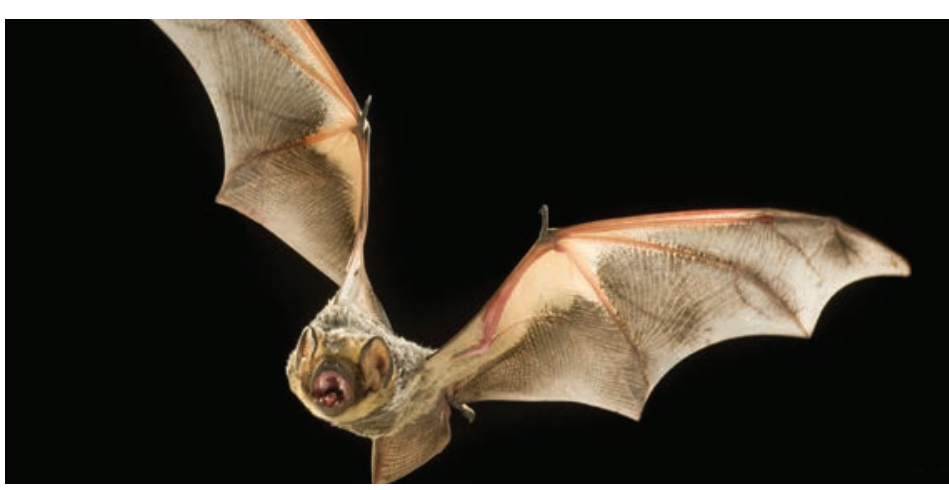

Figure 1. Hoary bats, pictured above, are one of the species associated with wind turbine-related deaths. Photo provided by Michael Durham/Minden Pictures, Bat Conservation International.

Barotrauma: Barotrauma describes injuries that occur when a bat (or other animal) encounters sudden and extreme changes in atmospheric pressure. The rapid pressure fluctuations can rupture air-containing structures in the bodies of mammals which causes internal bleeding and, potentially, death. In 2004, Durr et al. [6] hypothesized that the low-pressure regions that form over the convex surfaces of rotating turbine blades and within vortices that are shed from the blade tips (shown in Figure 2) might cause pressure fluctuations of sufficient magnitude to injure bats that fly too close to operating turbines.

A study by Baerwald et al. [4] was the first to find evidence for barotrauma as a cause of bat death. Baerwald and her coauthors studied dead bats found near operating turbines and found that more than $50 \%$ of such bats had internal hemorrhaging characteristic of barotrauma, without any external signs of impact trauma. The researchers concluded that barotrauma is responsible for a significant number of bat deaths. Even though a later study by Grodsky et al. [10] provided less conclusive results, the findings of Baerwald et al. [4] received widespread publicity and it has become an accepted fact in many quarters that barotrauma causes a significant percentage of wind turbine-related bat deaths.

\section{Recent Research Calls into Question the Barotrauma Hypothesis}

New research has provided quantitative data that indicates barotrauma is not a major cause of bat deaths around operating turbines. Rollins et al. [11] used forensic techniques, including autopsy and radiology, and found that while the barotrauma hypothesis could not be dismissed outright, $94 \%$ of bat deaths were directly attributable to impact trauma, and only $6 \%$ could 
be explained by barotrauma. Moreover, Rollins et al. [11] found that the methods in previous studies used to diagnose barotrauma could result in the misdiagnosis of barotrauma - due to the degradation of tissue before it was analyzed and because radiology was not used to check for internal signs of impact trauma. In addition, NREL researchers Houck et al. [12] used computational fluid dynamics simulations to study the range of pressure variations that bats experience when flying in the vicinity of an operating utility-scale wind turbine. The results of Houck et al. [12] (see Figure 3) suggest that the pressure changes near an operating turbine are at least an order of magnitude below the threshold where fatality is expected.

\section{Conclusions}

Impact trauma from direct collision and barotrauma are the two leading theories to explain the unexpectedly high fatality rates of migratory bats around operating wind turbines. While preliminary research [4], [10] suggested that barotrauma was responsible for a significant fraction of turbine-related deaths, more recent research that used advanced forensic pathology [11] and computational fluid dynamics simulations [12] indicate that impact trauma is responsible for the vast majority of turbinerelated bat deaths and that barotrauma is likely a minor etiology.

\section{The Need for Follow-0n Research}

Further research is needed before scientists can conclusively discount barotrauma as a significant cause of turbine-related deaths. Specifically, follow-on research that quantifies the magnitude of survivable pressure fluctuations would help confirm or deny the conclusions of Houck et al. [12]. It also remains unclear if repeated exposure to nonfatal barotrauma might cause injury and delayed fatality that cannot be detected by gathering dead bats from around wind facilities. Studying the

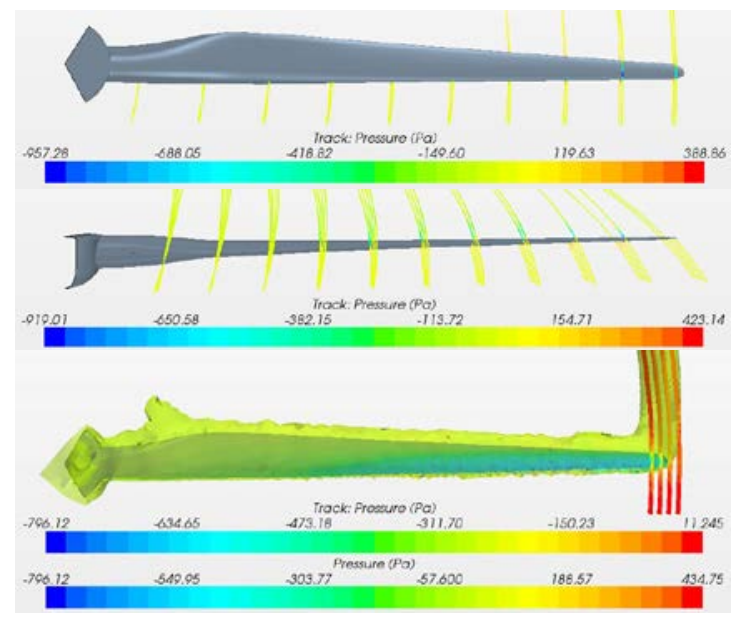

Figure 3. Possible bat flight paths around a utility scale turbine blade operating at a wind speed of $5 \mathrm{~m} / \mathrm{s}$. The colors of the flight paths indicate the pressure fluctuations that will be experienced by the bat. As described in the text, these pressure changes are much lower than the threshold where fatality is expected. delayed effects of barotrauma will, however, pose a significant challenge to researchers because tracking bats and diagnosing barotrauma after they fly away from wind farms will be difficult, although new research technologies [13] are making this task more achievable. Annotated Bibliography," 2012.

[2] T. H. Kunz, E. B. Arnett, W. P. Erickson, A. R. Hoar, G. D. Johnson, R. P. Larkin, M. D. Strickland, R. W. Thresher, and M. D. Tuttle, "Ecological impacts of wind energy development on bats: questions, research needs, and hypotheses," Front. Ecol. Environ., vol. 5, no. 6, pp. 315-324, 2007.

[3] P. H.-S. Jen and J. K. McCarty, "Bats avoid moving objects more successfully than

[4] E. F. Baerwald, G. H. D'Amours, B. J. Klug, and R. M. R. Barclay, "Barotrauma is a significant cause of bat fatalities at wind turbines," Curr. Biol., vol. 18, no. 16, pp. R695-R696, Aug. 2008.

[5] G. D. Johnson, W. P. Erickson, M. DALE STRICKLAND, M. F. Shepherd, D. A. Shepherd, and S. A. Sarappo, "Mortality of bats at a large-scale wind power development at Buffalo Ridge, Minnesota," Am. Midl. Nat., vol. 150, no. 2, pp. 332-342, 2003.

[6] T. Durr and L. Bach, "BAT DEATHS AND WIND TURBINES - A REVIEW OF CURRENT KNOWLEDGE, AND OF THE INFORMATION AVAILABLE IN THE DATABASE FOR GERMANY."

[7] P. M. Cryan and R. M. Barclay, "Causes of bat fatalities at wind turbines: hypotheses and predictions," J. Mammal., vol. 90, no. 6, pp. 1330-1340, 2009.

[8] C. V. Long, J. A. Flint, and P. A. Lepper, "Wind turbines and bat mortality: Doppler shift profiles and ultrasonic bat-like pulse reflection from moving turbine blades," J. Acoust. Soc. Am., vol. 128, p. 2238, 2010.

[9] J. W. Horn, E. B. Arnett, and T. H. Kunz, "Behavioral responses of bats to operating wind turbines,” J. Wildl. Manag., vol. 72, no. 1, pp. 123-132, 2008.

[10] S. M. Grodsky, M. J. Behr, A. Gendler, D. Drake, B. D. Dieterle, R. J. Rudd, and N. L. Walrath, "Investigating the causes of death for wind turbine-associated bat fatalities," J. Mammal., vol. 92, no. 5, pp. 917-925, 2011.

[11] K. E. Rollins, D. K. Meyerholz, G. D. Johnson, A. P. Capparella, and S. S. Loew, “A forensic investigation into the etiology of bat mortality at a wind farm: barotrauma or traumatic injury?," Vet. Pathol. Online, vol. 49, no. 2, pp. 362-371, 2012.

[12] Houck, Dan, "Computational fluid dynamics simulations of bats flying near operating wind turbines: Quantification of pressure-time histories of likely flight paths". Available through the U.S. DOE Office of Science, Office of Workforce Development for Teachers and Scientists Application Review System (WARS), 2012.

[13] O'Shea, T. J. ; Bogan, M. A., "Monitoring Trends in Bat Populations of the United States and Territories: Problems and Prospects," 2013.

Photos front page, top row, left to right: Dennis Schroeder, NREL 19007; Lee Jay Fingersh, NREL 15005; Warren Gretz, NREL 12415;
[1] U.S. Geological Survey, "Bats and Wind Energy — A Literature Synthesis and stationary ones," 1978. Lee Jay Fingersh, NREL 14691; Dennis Schroeder, NREL 18937
National Renewable Energy Laboratory

15013 Denver West Parkway, Golden, Colorado 80401

303-275-3000 - www.nrel.gov 